\title{
Upregulation of basic fibroblast growth factor in smokers with chronic bronchitis
}

\author{
F. Guddo*, A.M. Vignola\#,†, M. Saetta", S. Baraldo", L. Siena\#, E. Balestro", R. Zuin`, \\ A. Papi $^{+}$, P. Maestrelli ${ }^{\S}$, L.M. Fabbri ${ }^{\ddagger}$, G. Bonsignore ${ }^{\#}$ and G. Turato
}

ABSTRACT: The aim of the study was to investigate the expression of basic fibroblast growth factor (bFGF) and its receptor, fibroblast growth factor receptor (FGFR)-1, in the central airways of smokers with chronic bronchitis.

The lobar bronchi from 17 subjects undergoing thoracotomy for solitary nodules were examined. All had a history of cigarette smoking, nine had symptoms of chronic bronchitis and airflow limitation, and eight were asymptomatic with normal lung function. Using immunohistochemical methods, bFGF and FGFR-1 expression in the total airway wall and the different airway compartments, i.e. bronchial glands, submucosal vessels and smooth muscle, was quantified. Moreover, to investigate the role of bFGF in angiogenesis, the number of submucosal vessels was quantified.

Smokers with chronic bronchitis had an increased bFGF expression in the total airway wall compared with asymptomatic smokers, which was mainly due to bFGF upregulation in bronchial glands. By contrast, the expression of FGFR-1 and the number of submucosal vessels was similar in the two groups of subjects examined.

In conclusion, smokers with chronic bronchitis have an increased expression of basic fibroblast growth factor in the central airways, which is mainly due to an increased expression in bronchial glands, suggesting the involvement of this growth factor in the pathogenesis of chronic bronchitis.

KEYWORDS: Airway remodelling, cigarette smoking, chronic obstructive pulmonary disease, fibroblast growth factor receptor-1

C hronic bronchitis is a clinical syndrome defined by chronic sputum production. The major risk factor for the development of chronic bronchitis is cigarette smoking, but the precise pathogenetic mechanisms of the disease are largely unknown. Chronic bronchitis is characterised by an airway inflammatory process involving epithelium, subepithelium, bronchial glands and bronchial smooth muscle [1-3]. This inflammatory response is associated with a structural airway remodelling, which includes hypertrophy of the submucosal glands, enlargement of smooth muscle mass, fibrosis of the airway wall, epithelial metaplasia and goblet cell hyperplasia [4-8]. An important component of airway remodelling is angiogenesis, which has been well documented in asthma but poorly investigated in chronic bronchitis [5, 9].

Over the last few years, several studies have highlighted the role of fibroblast growth factors (FGFs) in regulating both inflammatory and remodelling processes in the lung [10-15]. FGFs represent one of the largest families of growth and differentiation factors for cells of mesodermal and neuroectodermal origin [16]. One of the best characterised members of the FGF family is basic FGF (bFGF), which is a pleiotropic polypeptide often regarded as a prototypic factor of the family. Among its different functions, bFGF is involved in mitotic activities, angiogenesis, tissue repair and inflammatory processes [16]. bFGF may be produced by several cell types, including fibroblasts, endothelial cells, macrophages, Tlymphocytes and mast cells [12, 13, 17, 18], and exerts its biological effects through an interaction with a high-affinity transmembrane receptor, fibroblast growth factor receptor (FGFR)-1 [16] In the lung, bFGF has been shown to be involved in several inflammatory diseases. An increased expression of bFGF has been found in the bronchoalveolar lavage and lung tissue of subjects with bronchial asthma and pulmonary fibrosis [10-12, 19]. Moreover, bFGF has been implicated in the pathogenesis of sarcoidosis [10] and post-transplant obliterative bronchiolitis [20].
AFFILIATIONS

*Pathology Unit, V. Cervello Hospital, and

\# Institute of Lung Pathophysiology, National Research Council, Palermo, -Dept of Cardiothoracic and Vascular Sciences, Section of Respiratory Diseases, and

${ }^{\S}$ Dept of Environmental Medicine and Public Health, University of Padova, Padova,

${ }^{+}$Dept of Clinical and Experimental Medicine, Section of Respiratory Diseases, University of Ferrara, Ferrara,

fDept of Oncology and Hematology, Section of Respiratory Diseases, University of Modena and Reggio Emilia, Modena, Italy.

CORRESPONDENCE

M. Saetta

Divisione di Pneumologia

Dipartimento di Scienze

Cardiologiche

Toraciche e Vascolari

Università degli Studi di Padova

Via Giustiniani 3

35128 Padova

Italy

Fax: 390498213701

E-mail: marina.saetta@unipd.it

Received:

May 162005

Accepted after revision:

January 302006

SUPPORT STATEMENT

This study was supported by the National Research Council (CNR), the Italian Ministry of University and Research (MIUR) and by the University of Padova (Padova, Italy).

European Respiratory Journal Print ISSN 0903-1936 Online ISSN 1399-3003 
Recently, KRANENBURG et al. [15] examined the expression of this growth factor in the bronchial walls of smokers with chronic obstructive pulmonary disease (COPD). The study showed that bFGF and its receptor FGFR-1 were upregulated in bronchial epithelium and bronchial smooth muscle, suggesting a role for the bFGF pathway in the airway remodelling characteristic of COPD [15].

In the current study, the expression of bFGF and its receptor in the whole airway wall and its different compartments, particularly in the bronchial glands, was evaluated. Moreover, to investigate its angiogenetic potential, the present authors examined whether the expression of bFGF and its receptor was related to the number of submucosal vessels.

\section{METHODS}

\section{Subjects}

The study population was composed of 17 subjects with a history of cigarette smoking who were undergoing lung resection for a solitary lesion. Nine had symptoms of chronic bronchitis and eight were asymptomatic (control smokers).

Chronic bronchitis was defined as cough and sputum production occurring on most days of the month for $\geqslant 3$ months $\cdot \mathrm{yr}^{-1}$ during the 2 yrs prior to the study. Subjects with chronic bronchitis had no exacerbations, which were defined as increased dyspnoea associated with a change in the quality and quantity of sputum that led the subject to seek medical attention during the month preceding the study [21]. All subjects in both groups had been free of acute upper respiratory tract infections, and none had received glucocorticoids or antibiotics within the month preceding surgery, or bronchodilators within the previous $48 \mathrm{~h}$. The subjects were nonatopic (i.e. they had negative skin tests for common allergen extracts) and had no past history of asthma or allergic rhinitis.

The study conformed with the Declaration of Helsinki, and informed written consent was obtained for each subject undergoing surgery. Each subject underwent an interview, chest radiography, ECG, routine blood tests, skin tests with common allergen extracts and pulmonary function tests in the week before surgery.

Pulmonary function tests were performed according to previously reported methodology [21]. Briefly, pulmonary function tests included measurements of forced expiratory volume in one second (FEV1) and forced vital capacity (FVC) in all of the subjects examined. In subjects with a baseline FEV1 $>80 \%$ predicted, inhalation challenge with methacholine was performed and the results were expressed as the provocative dose that elicited a $20 \%$ decline in FEV1 (PD20). In order to assess the reversibility of airway obstruction in subjects with a baseline FEV1 $<80 \%$ pred, the FEV1 measurement was repeated $15 \mathrm{~min}$ after the inhalation of $200 \mu \mathrm{g}$ of salbutamol.

\section{Histology}

One ring from each subject was taken from the lobar or segmental bronchus of the lobe obtained at surgery, away from the tumour site, fixed in $4 \%$ formaldehyde and embedded in paraffin as previously described [2].
The expression of bFGF and its receptor FGFR-1, as well as the number of submucosal vessels were detected by immunohistochemical avidin-biotinylated peroxidase method. The following antibodies were used for identification of vessels: polyclonal anti-bFGF antibody (Sigma BioScience, St. Louis, MO, USA), monoclonal anti-FGFR-1 antibody (Santa Cruz Biotechnology Inc., Santa Cruz, CA, USA) and monoclonal anti-CD34 antibody (Dakopatts, Copenhagen, Denmark). As a positive control, nonsmall cell lung cancer sections were used, which are known to be immunoreactive for bFGF and FGFR-I. For a negative control, the specific primary monoclonal antibody was omitted.

Quantitative assessment of bFGF and FGFR-1 expression was performed using a stereological method as previously described [13, 22]. In each subject, 150 microscope fields (total wall) were evaluated as follows: 50 in the bronchial glands; 50 in the bronchial smooth muscle; and 50 in the submucosal vessels. Point counting was performed in each field using light microscopy under $\times 1,000$ magnification using a 30-point Weibel grid. The percentage of points falling on positive staining was determined in the total wall and in the separate compartments (bronchial glands, smooth muscle, submucosal vessels) as follows: $\mathrm{Pi} / \mathrm{Pt} \times 100$, where $\mathrm{Pi}$ is the number of points that fell on positive staining and $\mathrm{Pt}$ is the total number of points counted. The results were expressed as per cent volume density, as previously described [13, 22].

A quantitative assessment of bFGF and FGFR-1 was also performed in the bronchial epithelium of the subjects with intact epithelium. The number of bFGF and FGFR-1 positive cells within the airway epithelium was counted and the results were expressed as number of positive cells $\cdot \mathrm{mm}^{-1}$ of basement membrane.

Submucosal vessels were assessed, recording the highest value of vessel count in the three highest vascularised microscopic fields as previously described [23], and expressing them as number of vessels $\cdot \mathrm{mm}^{-2}$ of tissue examined.

Reid's index was calculated as the ratio between the maximum thickness of each bronchial gland and the bronchial wall thickness, as measured from the basement membrane to inner perichondrium along a single axis. Smooth muscle proportion was calculated as the ratio between thickness of smooth muscle and bronchial wall thickness.

To avoid observer bias, the cases were coded and measurements were made without knowledge of clinical data.

\section{Statistical analysis}

Differences between groups were analysed using ANOVA for clinical data and the Mann-Whitney U-test group data for histological results. Correlation coefficients were calculated using Spearman's rank test. The Wilcoxon signed-rank test was used to compare bFGF and FGFR1 expression in the different compartments. p-Values $\leqslant 0.05$ were accepted as significant. Group data were expressed as mean \pm SEM or as median (range) where appropriate.

\section{RESULTS}

\section{Clinical findings}

The characteristics of chronic bronchitics and control smokers are reported in table 1 . All subjects with chronic bronchitis had 


\begin{tabular}{|c|c|c|}
\hline & Chronic bronchitics & Control smokers \\
\hline Males $\mathbf{n}$ & 9 & 8 \\
\hline Age yrs & $68 \pm 3$ & $69 \pm 2$ \\
\hline Smoking history pack-yrs & $57 \pm 8$ & $45 \pm 5$ \\
\hline FEV $1 \%$ pred & $68 \pm 3^{\star *}$ & $98 \pm 4$ \\
\hline $\mathrm{FEV}_{1 / \text { FVC } \%}$ & $67 \pm 2^{\star \star}$ & $78 \pm 3$ \\
\hline $\mathrm{Pa}, \mathrm{O}_{2} \mathrm{mmHg}$ & $85 \pm 4$ & $89 \pm 3$ \\
\hline $\mathrm{Pa}, \mathrm{CO}_{2} \mathrm{mmHg}$ & $41 \pm 2$ & $36 \pm 3$ \\
\hline \multicolumn{3}{|c|}{$\begin{array}{l}\text { Data are presented as mean } \pm \mathrm{SEM} \text {, unless otherwise stated. } \mathrm{FEV} 1 \text { : forced } \\
\text { expiratory volume in one second; \% pred: \% of predicted; } \mathrm{FVC} \text { : forced vital } \\
\text { capacity; } \mathrm{Pa}, \mathrm{O}_{2} \text { : arterial oxygen tension; } \mathrm{Pa}_{1} \mathrm{CO}_{2} \text { : arterial carbon dioxide tension. } \\
\text { **: significantly different from control smokers }(\mathrm{p}<0.01) .1 \mathrm{mmHg}=0.133 \mathrm{kPa} \text {. }\end{array}$} \\
\hline
\end{tabular}

an FEV1 $<80 \%$ pred, ranging $56-79 \%$ pred, with an average response to bronchodilator of 5\% (range 0-13\%). All control smokers had normal lung function, with an FEV1 ranging 86$116 \%$ pred, and reactivity to methacholine within the normal range (PD20 $>1.4 \mu \mathrm{g}$ methacholine). Subjects with chronic bronchitis had a significantly lower value of FEV1 \% pred and FEV1/FVC \% ratio than control smokers. The two groups of subjects were similar with regard to age, sex, smoking history, arterial oxygen tension and arterial carbon dioxide tension values.

Data regarding underlying cancer were collected in six out of nine patients with chronic bronchitis and in six out of eight control smokers. All subjects of both groups had squamous cell carcinoma except three (one smoker with chronic bronchitis and two control smokers) who were referred to lobectomy for suspected carcinoma, which was revealed to be a benign tumour at the pathological examination. The lesion was localised in the lung parenchyma in three control smokers and four smokers with chronic bronchitis, whereas it was localised in a lobar or segmental bronchus in the remaining cases. All subjects were staged as tumour (T)1 or T2; the relative proportion of each being similar in smokers with chronic bronchitis and control smokers.

\section{Histological findings}

The quantification of the expression of bFGF and of its receptor, FGFR-1, was satisfactory in all subjects except one

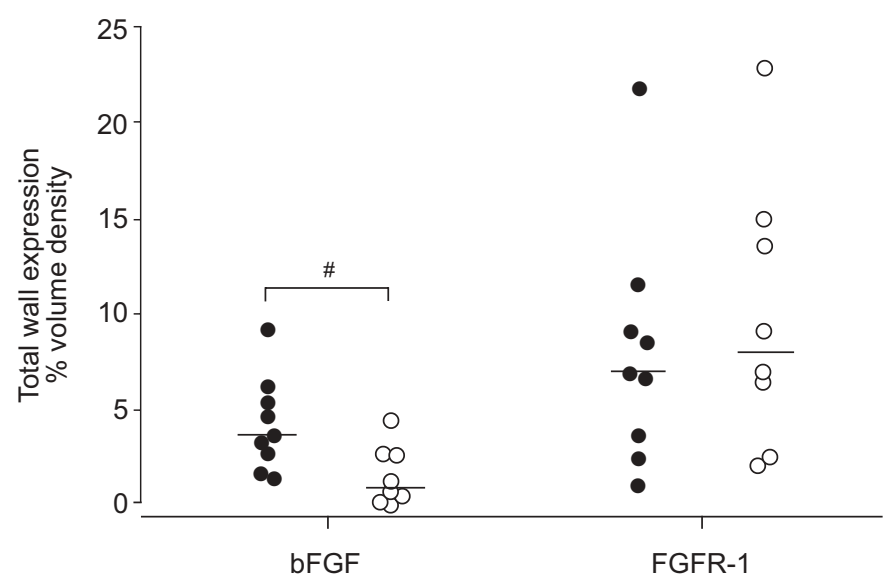

FIGURE 1. Individual measurements of total basic fibroblast growth factor (bFGF) expression in smokers with chronic bronchitis $(\bullet)$ and control smokers $(\bigcirc)$. Horizontal bars represent median values. FGFR: fibroblast growth factor receptor. \# : $p=0.02$.

with chronic bronchitis, in whom the bronchial glands could not be examined because of the lack of gland tissue.

The expression of bFGF in the total wall of central airways was increased in subjects with chronic bronchitis as compared with control smokers (fig. 1). When the different wall compartments were examined, e.g. bronchial glands, smooth muscle and submucosal vessels (fig. 2), the increased expression of bFGF remained significant only in the bronchial glands (fig. 3). By contrast, the expression of the receptor FGFR-1 was similar in the two groups of subjects, both in the total wall and in each of the compartments examined (figs 1 and 4).

Among the three compartments examined, bronchial glands showed the highest reactivity for bFGF and FGFR-1. Indeed, bFGF expression in bronchial glands was higher than in bronchial smooth muscle or submucosal vessels, both in subjects with chronic bronchitis $(\mathrm{p}=0.03$ and $\mathrm{p}=0.02$, respectively) and control smokers ( $p=0.02$ and $p=0.08$, respectively). Similarly, FGFR-1 expression in bronchial glands was higher than in bronchial smooth muscle or submucosal vessels, both in subjects with chronic bronchitis $(\mathrm{p}<0.01$ and $\mathrm{p}<0.01$, respectively) and control smokers $(\mathrm{p}<0.05$ and $\mathrm{p}<0.01$, respectively).

Analysis of bronchial epithelium could not be performed in four smokers with chronic bronchitis and one control smoker
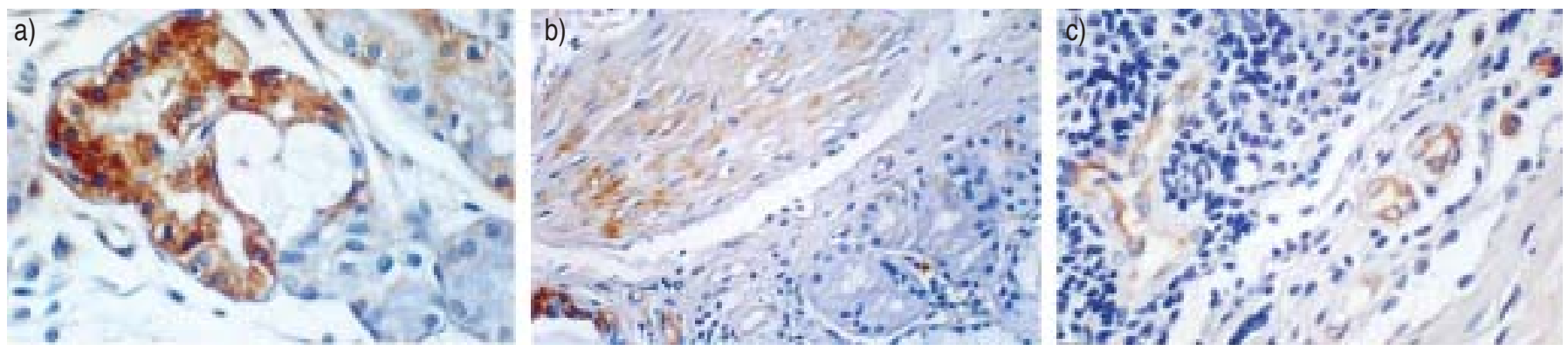

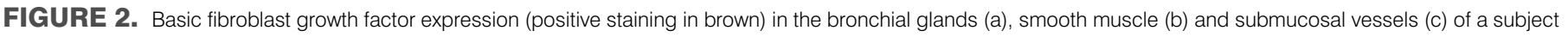
with chronic bronchitis. 


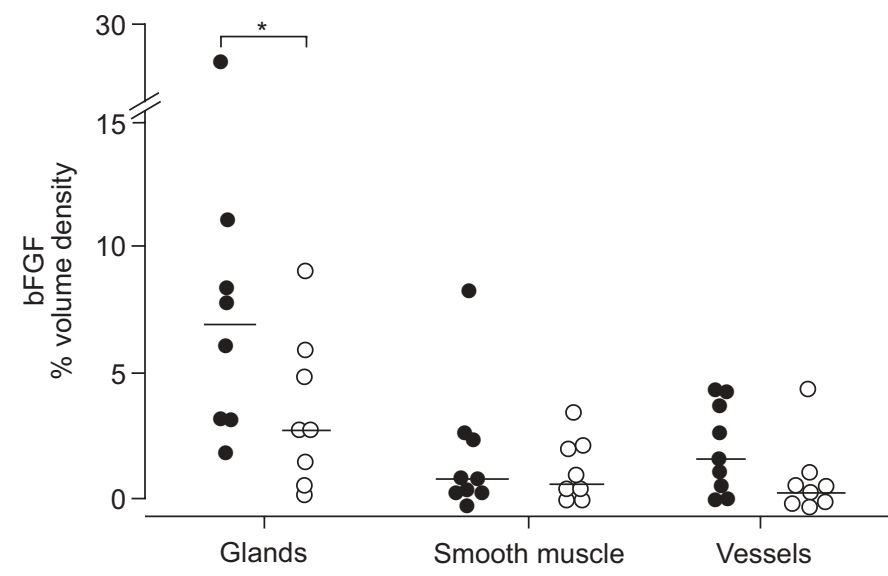

FIGURE 3. Individual measurements of basic fibroblast growth factor (bFGF) expression in bronchial glands, smooth muscle and submucosal vessels in smokers with chronic bronchitis $(\bullet)$ and control smokers $(\bigcirc)$. Horizontal bars represent median values. ${ }^{*}: p<0.05$.

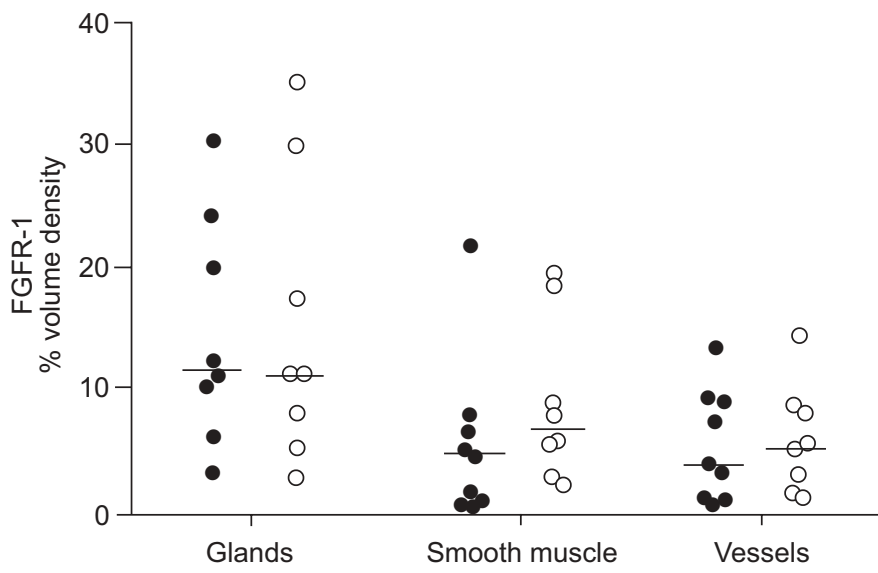

FIGURE 4. Individual measurements of fibroblast growth factor receptor (FGFR)-1 expression in bronchial glands, smooth muscle and submucosal vessels in smokers with chronic bronchitis $(\bullet)$ and control smokers $(\bigcirc)$. Horizontal bars represent median values.

because of epithelial denudation. The epithelial expression of bFGF was not significantly different in subjects with chronic bronchitis as compared with control smokers (median (range) 56 (30-145) versus $57(18-102)$ cells $\left.\cdot \mathrm{mm}^{-1}\right)$. Similarly, the expression of the receptor FGFR-1 was not significantly different in the two groups of subjects examined (54 (40-70) versus $73(29-132)$ cells $\left.\cdot \mathrm{mm}^{-1}\right)$.

When the structural changes were examined, the number of submucosal vessels, the Reid's index and the proportion of smooth muscle were not found to be significantly different in subjects with chronic bronchitis and control smokers (table 2).

When all the subjects were grouped together, the total wall expression of bFGF showed a significant positive correlation with the number of vessels $(r=0.47 ; p=0.05$; fig. 5$)$, as did the expression of $b F G F$ in bronchial glands $(r=0.49 ; p=0.05)$. This latter correlation remained significant only when smokers with chronic bronchitis were considered $(\mathrm{r}=0.78 ; \mathrm{p}=0.03)$.
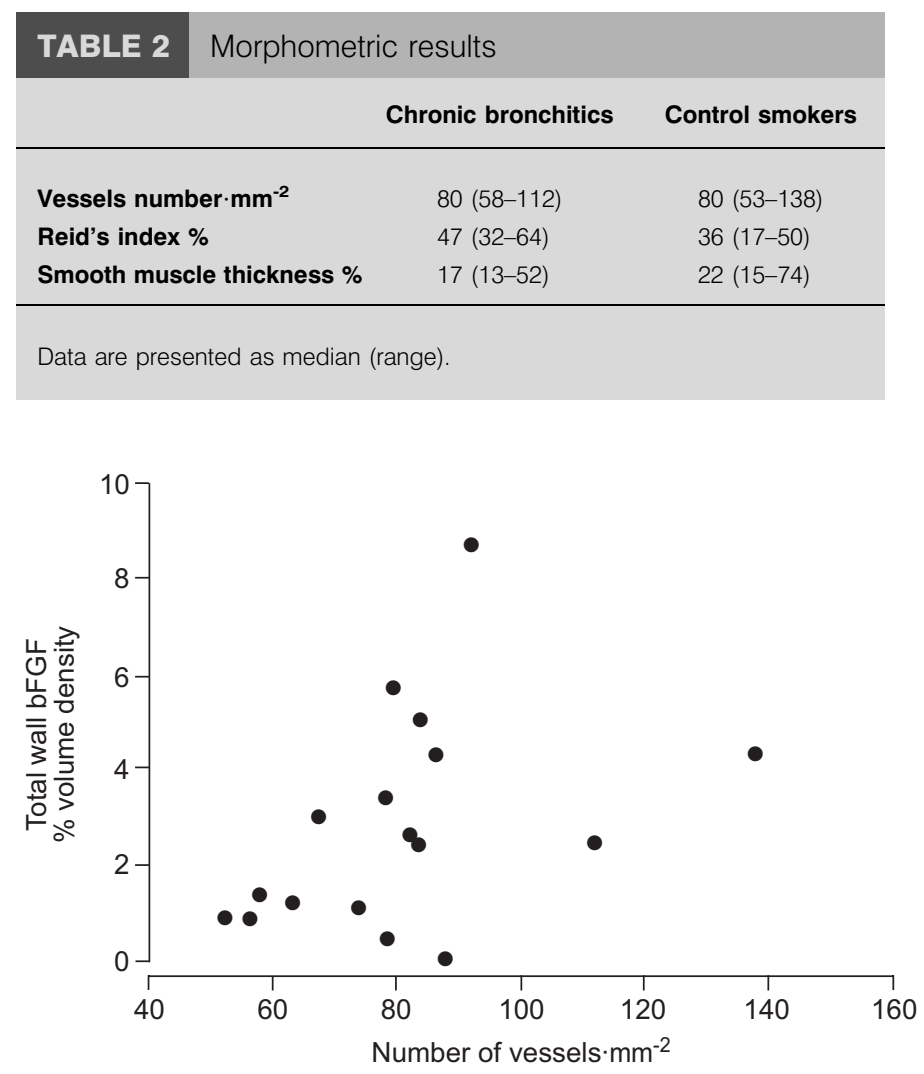

FIGURE 5. Relationship between basic fibroblast growth factor (bFGF) expression in the bronchial wall and the number of submucosal vessels (Spearman's rank correlation). $p<0.05 ; r=0.47$.

Moreover, bFGF expression in smooth muscle showed a positive correlation with Reid's index in all of the studied subjects $(r=0.55 ; p=0.03)$, which remained significant only when smokers with chronic bronchitis were considered $(\mathrm{r}=0.73 ; \mathrm{p}=0.05)$. Finally, a positive correlation was observed in bronchial glands between the expression of bFGF and its receptor FGFR-1 $(r=0.52 ; p=0.04)$, which remained significant only when smokers with chronic bronchitis were considered $(r=0.73 ; p=0.05)$. No significant correlations were found between histological parameters and functional data.

\section{DISCUSSION}

The current study shows that smokers with chronic bronchitis have an increased expression of bFGF in central airways, which is mainly due to an enhanced expression in the gland compartment.

The precise source of bFGF in the central airways is unknown, but previous reports have shown that several cell types may produce this growth factor and, among them, inflammatory cells. In particular, it has been shown that T-lymphocytes and macrophages, which are increased in the central airways of smokers with chronic bronchitis [1], can secrete bFGF [17, 18]. Therefore, it is plausible that these inflammatory cells may contribute to the upregulation of bFGF that was observed in the current study.

Among its potential effects, bFGF may induce the migration and proliferation of endothelial cells, leading to angiogenesis 
[16]. New vessel formation is an important component of airway remodelling, which has been well documented in bronchial asthma $[5,9]$ but insufficiently investigated in COPD [5]. The current finding of a similar number of submucosal vessels in smokers with chronic bronchitis and asymptomatic smokers is in agreement with the results by KuWANO et al. [5] who reported a similar number of vessels in the peripheral airways of subjects with COPD and controls. Interestingly, despite the lack of difference between the two groups of subjects, the present authors found that the number of submucosal vessels was positively correlated with the expression of bFGF, suggesting an angiogenetic activity for this growth factor in smokers. A possible explanation for the lack of difference in the number of vessels in the current study is that all subjects in the control group were heavy smokers, and smoking itself is able to induce an airway inflammatory process, which may potentially promote angiogenesis [24] However, it must be highlighted that, without a proper control group of nonsmoking subjects, a firm conclusion cannot be drawn on the presence of angiogenesis in smokers. Unfortunately, the current study lacks such a control group, since the study population consisted of patients undergoing thoracotomy for lung cancer, which is less frequent among nonsmokers than it is in smokers.

When bFGF expression in the different compartments of central airways was quantified, an upregulation of this growth factor in the bronchial glands of smokers with chronic bronchitis was found. Chronic bronchitis is usually associated with hypertrophy of bronchial glands, a pathological feature traditionally considered to account for the increased sputum production $[25,26]$. It is somewhat surprising that, in the current study, the enhanced bFGF expression in smokers with symptoms of chronic bronchitis was not associated with gland hypertrophy as measured by Reid's index. However, this finding is in agreement with previous reports showing a lack of correlation between sputum production and gland hypertrophy in smokers [27]. In this context, it is interesting to note that the inflammatory response involving the bronchial glands has shown a better concordance with mucus hypersecretion than gland size per se [26, 28]. In the bronchial glands, this inflammatory response is characterised by neutrophils, mast cells, macrophages and CD8 T-lymphocytes [2, 29], all of which can potentially produce bFGF $[12,17,18,30]$. Therefore, it is conceivable that the increased expression of bFGF that was observed in the bronchial glands of smokers with chronic bronchitis may be due to the inflammatory cells infiltrating the glandular compartment. Neutrophils are an important component of this inflammatory response, and it has been shown that bFGF may regulate the neutrophil recruitment by modulating the expression of adhesion molecules on these cells [31]. Interestingly, neutrophil elastase is able to release, and therefore activate, the bFGF bound within the extracellular matrix [32], suggesting that the interaction between this growth factor and neutrophils may create a self-maintaining loop.

In the current study, the upregulation of bFGF in the bronchial glands of subjects with chronic bronchitis was not accompanied by the increased expression of its receptor FGFR-1. Although previous observations have suggested that bFGF is able to upregulate the expression of its receptor FGFR-1 via autocrine signals [33], this is not the only mechanism. Indeed, the regulation of FGFR-1 expression is a complex mechanism, which is not completely understood and can be influenced by many different factors, such as hypoxaemia, cell phenotype or changes in the extracellular matrix environment [34-36]. These confounding factors may explain why, in the present study, the increased expression of bFGF was not accompanied by an increase in its receptor FGFR-1.

Surprisingly, no difference in the expression of bFGF and its receptor in the bronchial smooth muscle of smokers with chronic bronchitis and control smokers was found. This finding appears to contrast with the results of a recent report by KRANENBURG et al. [15], showing that both bFGF and its receptor FGFR-1 were upregulated in the bronchial smooth muscle of subjects with COPD. However, there are important clinical and methodological differences between the two studies that may have influenced the results. Indeed, in the current study, the subjects were selected on the basis of chronic bronchitis symptoms, whereas in the study by KRANENBURG et al. [15] they were selected on the basis of airflow limitation, regardless of the presence of chronic bronchitis. Although the two conditions can share some pathogenetic traits, there can be some discrepancies as well. Moreover, the current authors used different antibodies and a different quantitative analysis to detect FGF and FGFR-1 expression, thus making a direct comparison between the two studies difficult. Despite this, the main finding of an increased bFGF expression in the central airways of smokers with chronic bronchitis confirms the observation by KRANENBURG et al. [15] and is consistent with their hypothesis that bFGF could be implied in the airway remodelling that characterises COPD. In a previous report, KRANENBURG et al. [14] showed that both bFGF and its receptor FGFR-1 were upregulated even in the pulmonary arteries of subjects with COPD, suggesting a role for the bFGF pathway in the vascular remodelling observed in the disease. In this context, the recent observations by SHUTE et al. [19] are of interest. These investigators demonstrated an increased expression of bFGF in bronchial biopsies of asthmatic subjects, indicating that, in asthma as with COPD, an upregulation of bFGF is present and may contribute to airway remodelling. However, the precise role of bFGF in the development of the structural changes characteristic of the two diseases still remains to be investigated. In particular, it is still unknown whether the increased bFGF expression that was observed in bronchial glands of smokers with COPD is present even in the bronchial glands of asthmatic subjects and is associated with mucus production in these subjects.

In the current study, although subjects with chronic bronchitis were selected only on the basis of the presence of symptoms, they all had fixed airflow limitation. Therefore, whether the observed upregulation of bFGF is related to chronic bronchitis or to airflow limitation still remains to be investigated. However, it should be highlighted that this distinction may be problematic, since the role of symptoms of chronic bronchitis in the development of chronic airflow limitation is still controversial. Traditionally, mucus hypersecretion has been considered irrelevant for the development of airflow limitation [37], and, more recently, it has been shown that chronic sputum production in smokers with normal lung function (Global Initiative for Chronic Obstructive Lung Disease stage 0) does not predict a subsequent establishment 
of airflow limitation [38]. Conversely, when COPD is established, as it is in the subjects of the present study, chronic sputum production has been found to be associated with both an excess of FEV1 decline and an increased risk of subsequent hospitalisation [38, 39], suggesting a role for mucus hypersecretion in the progression of the disease.

In any study on surgically resected specimens of patients with lung cancer, the presence of cancer itself may influence the results. However, as compared with bronchial biopsy, which samples only a small portion of the bronchial wall, surgical specimens allow for a better examination of the whole central airways. Moreover, as a result of examining only tissue away from the tumour site and having included subjects with lung cancer in the control group, the current authors are confident that the finding of an increased bFGF expression in the central airways of subjects with chronic bronchitis is valid.

When considering the relationship between lung cancer and COPD, it is noteworthy that COPD, which is characterised by chronic lung inflammation, is associated with an increased risk of lung cancer [40], thus suggesting a pathogenetic link between tumour and inflammation. Interestingly, bFGF has the potential to stimulate tumour proliferation by promoting angiogenesis [16]. Therefore, it is conceivable that this growth factor could have a key role in the association observed between lung cancer and COPD.

In conclusion, smokers with chronic bronchitis and airflow limitation have an increased expression of basic fibroblast growth factor in the central airways, which is mainly due to an enhanced expression in the bronchial gland compartment. These results suggest that basic fibroblast growth factor may have a role in promoting mucus hypersecretion in smokers. However, further studies are required to clarify the multiple roles played by basic fibroblast growth factor in the pathogenesis of chronic bronchitis and chronic obstructive pulmonary disease.

\section{REFERENCES}

1 Saetta M, Di Stefano A, Maestrelli P, et al. Activated Tlymphocytes and macrophages in bronchial mucosa of subjects with chronic bronchitis. Am Rev Respir Dis 1993; 147: 301-306.

2 Saetta M, Turato G, Facchini FM, et al. Inflammatory cells in the bronchial glands of smokers with chronic bronchitis. Am J Respir Crit Care Med 1997; 156: 1633-1639.

3 Baraldo S, Turato G, Badin C, et al. Neutrophilic infiltration within the airway smooth muscle in patients with COPD. Thorax 2004; 59: 308-312.

4 Cosio M, Ghezzo H, Hogg JC, et al. The relations between structural changes in small airways and pulmonaryfunction tests. N Engl J Med 1978; 298: 1277-1281.

5 Kuwano K, Bosken CH, Pare PD, Bai TR, Wiggs BR, Hogg JC. Small airways dimensions in asthma and in chronic obstructive pulmonary disease. Am Rev Respir Dis 1993; 148: 1220-1225.

6 Saetta M, Turato G, Baraldo S, et al. Goblet cell hyperplasia and epithelial inflammation in peripheral airways of smokers with both symptoms of chronic bronchitis and chronic airflow limitation. Am J Respir Crit Care Med 2000; 161: 1016-1021.

7 Jeffery PK. Comparison of the structural and inflammatory features of COPD and asthma. Giles F. Filley Lecture. Chest 2000; 117: Suppl. 1, 251S-260S.

8 Hogg JC, Chu F, Utokaparch S, et al. The nature of smallairway obstruction in chronic obstructive pulmonary disease. N Engl J Med 2004; 350: 2645-2653.

9 Chetta A, Zanini A, Foresi A, et al. Vascular component of airway remodeling in asthma is reduced by high dose of fluticasone. Am J Respir Crit Care Med 2003; 167: 751-757.

10 Inoue Y, King TE Jr, Tinkle SS, Dockstader K, Newman LS. Human mast cell basic fibroblast growth factor in pulmonary fibrotic disorders. Am J Pathol 1996; 149: 2037-2054.

11 Hoshino M, Takahashi M, Aoike N. Expression of vascular endothelial growth factor, basic fibroblast growth factor, and angiogenin immunoreactivity in asthmatic airways and its relationship to angiogenesis. J Allergy Clin Immunol 2001; 107: 295-301.

12 Redington AE, Roche WR, Madden J, et al. Basic fibroblast growth factor in asthma: measurement in bronchoalveolar lavage fluid basally and following allergen challenge. $J$ Allergy Clin Immunol 2001; 107: 384-387.

13 Inoue $\mathrm{Y}$, King TE Jr, Barker E, Daniloff E, Newman LS. Basic fibroblast growth factor and its receptors in idiopathic pulmonary fibrosis and lymphangioleiomyomatosis. Am J Respir Crit Care Med 2002; 166: 765-773.

14 Kranenburg AR, De Boer WI, Van Krieken JH, et al. Enhanced expression of fibroblast growth factors and receptor FGFR-1 during vascular remodeling in chronic obstructive pulmonary disease. Am J Respir Cell Mol Biol 2002; 27: 517-525.

15 Kranenburg AR, Willems-Widyastuti A, Mooi WJ, et al. Chronic obstructive pulmonary disease is associated with enhanced bronchial expression of FGF-1, FGF-2, and FGFR-1. J Pathol 2005; 206: 28-38.

16 Cronauer MV, Schulz WA, Seifert HH, Ackermann R, Burchardt M. Fibroblast growth factors and their receptors in urological cancers: basic research and clinical implications. Eur Urol 2003; 43: 309-319.

17 Henke C, Marineili W, Jessurun J, et al. Macrophage production of basic fibroblast growth factor in the fibroproliferative disorder of alveolar fibrosis after lung injury. Am J Pathol 1993; 143: 1189-1199.

18 Blotnick S, Peoples GE, Freeman MR, Eberlein TJ, Klagsbrun M. T lymphocytes synthesize and export heparin-binding epidermal growth factor-like growth factor and basic fibroblast growth factor, mitogens for vascular cells and fibroblasts: differential production and release by CD4+ and CD8+ T cells. Proc Natl Acad Sci USA 1994; 91: 2890-2894.

19 Shute JK, Solic N, Shimizu J, McConnell W, Redington AE, Howarth PH. Epithelial expression and release of FGF-2 from heparan sulphate binding sites in bronchial tissue in asthma. Thorax 2004; 59: 557-562.

20 al-Dossari GA, Jessurun J, Bolman RM 3rd, et al. Pathogenesis of obliterative bronchiolitis. Possible roles of platelet-derived growth factor and basic fibroblast growth factor. Transplantation 1995; 59: 143-145. 
21 Saetta M, Di Stefano A, Maestrelli P, et al. Airway eosinophilia in chronic bronchitis during exacerbations. Am J Respir Crit Care Med 1994; 150: 1646-1652.

22 Hyde DM, King TE Jr, McDermott T, et al. Idiopathic pulmonary fibrosis. Quantitative assessment of lung pathology. Comparison of a semiquantitative and a morphometric histopathologic scoring system. Am Rev Respir Dis 1992; 146: 1042-1047.

23 Weidner $\mathrm{N}$. Intratumor microvessel density as a prognostic factor in cancer. Am J Pathol 1995; 147: 9-19.

24 Jackson JR, Seed MP, Kircher CH, Willoughby DA, Winkler JD. The codependence of angiogenesis and chronic inflammation. FASEB J 1997; 11: 457-465.

25 Reid LM. Pathology of chronic bronchitis. Lancet 1954; 266: 274-278.

26 Zhu J, Majumdar S, Qiu Y, et al. Interleukin-4 and interleukin-5 gene expression and inflammation in the mucus-secreting glands and subepithelial tissue of smokers with chronic bronchitis. Lack of relationship with CD8(+) cells. Am J Respir Crit Care Med 2001; 164: 2220-2228.

27 Nagai A, West WW, Thurlbeck WM. The National Institutes of Health Intermittent Positive-Pressure Breathing trial: pathology studies. II. Correlation between morphologic findings, clinical findings, and evidence of expiratory air-flow obstruction. Am Rev Respir Dis 1985; 132: 946-953.

28 Mullen JB, Wright JL, Wiggs BR, Pare PD, Hogg JC. Reassessment of inflammation of airways in chronic bronchitis. BMJ (Clin Res Ed) 1985; 291: 1235-1239.

29 Pesci A, Rossi GA, Bertorelli G, Aufiero A, Zanon P, Olivieri D. Mast cells in the airway lumen and bronchial mucosa of patients with chronic bronchitis. Am J Respir Crit Care Med 1994; 149: 1311-1316.

30 Takamiya M, Saigusa K, Nakayashiki N, Aoki Y. Studies on mRNA expression of basic fibroblast growth factor in wound healing for wound age determination. Int J Legal Med 2003; 117: 46-50.

31 Takagi S, Takahashi K, Katsura Y, Matsuoka T, Ohsaka A. Basic fibroblast growth factor modulates the surface expression of effector cell molecules and primes respiratory burst activity in human neutrophils. Acta Haematol 2000; 103: 78-83.

32 Rich CB, Nugent MA, Stone P, Foster JA. Elastase release of basic fibroblast growth factor in pulmonary fibroblast cultures results in down-regulation of elastin gene transcription. A role for basic fibroblast growth factor in regulating lung repair. J Biol Chem 1996; 271: 23043-23048.

33 Estival A, Monzat V, Miquel K, et al. Differential regulation of fibroblast growth factor (FGF) receptor-1 mRNA and protein by two molecular forms of basic FGF. Modulation of FGFR-1 mRNA stability. J Biol Chem 1996; 271: 5663-5670.

34 Ganat Y, Soni S, Chacon M, Schwartz ML, Vaccarino FM. Chronic hypoxia up-regulates fibroblast growth factor ligands in the perinatal brain and induces fibroblast growth factor-responsive radial glial cells in the subependymal zone. Neuroscience 2002; 112: 977-991.

35 Bikfalvi A, Klein S, Pintucci G, Quarto N, Mignatti P, Rifkin DB. Differential modulation of cell phenotype by different molecular weight forms of basic fibroblast growth factor: possible intracellular signaling by high molecular weight forms. J Cell Biol 1995; 129: 233-243.

36 Tsou R, Isik F. Integrin activation is required for VEGF and FGF receptor protein presence on human microvascular endothelial cells. Mol Cell Biochem 2001; 224: 81-89.

37 Peto R, Speizer FE, Cochrane AL, et al. The relevance in adults of air-flow obstruction, but not of mucus hypersecretion, to mortality from chronic lung disease. Results from 20 years of prospective observation. Am Rev Respir Dis 1983; 128: 491-500.

38 Vestbo J, Lange P. Can GOLD Stage 0 provide information of prognostic value in chronic obstructive pulmonary disease? Am J Respir Crit Care Med 2002; 166: 329-332.

39 Vestbo J, Prescott E, Lange P. Association of chronic mucus hypersecretion with FEV1 decline and chronic obstructive pulmonary disease morbidity. Copenhagen City Heart Study Group. Am J Respir Crit Care Med 1996; 153: 1530-1535.

40 Papi ACG, Caramori G, Guzzinati I, et al. COPD increases the risk of squamous histological subtype in smokers who develop non-small-cell lung carcinoma. Thorax 2004; 59: 679-681. 